\title{
Notas sobre el Proceso Penal
}

\author{
por el Dr. DOMINGO GARCIA RADA \\ V.ocal de la Corte Suprema de Justicia, \\ Decano de la Facultad de Derecho y Ciencias Políticas de la Pontificiat \\ Universidad Católica
}

1. EL PROCEDIMIENTO PENAL EN EL CAMPO DEL DERECHO, RELACIONES ENTRE PROCESO Y PENA, DIFERENCIAS ENTRE PROCESO PENAL $Y$ PROCESO CIVIL, AUTONOMIA DEL PROCESO PENAL.

En la sociedad se presentan a menudo conflictos de intereses, los que pueden ser de muchas clases, desde una discusión científica hasta la interpretación de un contrato. Pero por más apasionados que sean es necescrio que los conflictos revistan trascendencia jurídica para que constituyan materia procesal. Una conversación deportiva, por acalorada que sea, no es materia suficiente para que exista un praceso, excepto que en el curso de ella se haya producido algún hecho que reclame la intervención de la jurisdicción v.g. una riña.

Producido el conflicto entre dos intereses contrapuestos, puede arreglarse de dos maneras: por obra de los propios litigantes, o mediante la decisión imperativa de un tercero.

En el primer caso -obra de los mismos interesados- el conflicto puede tener solución particular, que es dada por las mismas partes; o bien una de ellos sacrifica su interés accediendo a la petición del contrario o bien impone su opinión sacrificando al contrario. El primer caso es lo que Carnelutti llama "auto-composición" o allanamiento; el segundo es la "auto-defensa" o legítima defensa; ambas son soluciones unilaterales que se diferencion por los motivos: altruista el primero, egoista el segundo. La auto-defensa es peligrosa y el Estado la prohibe. La auto-composición es la más completa y satisfactoria, pero se da pocas veces. La solución imparcial es el Proceso, la más frecuente, accesible y fócil de las soluciones y la que ofrece mayores posibilidades de alcanzar un resultado. justo. En conclusión todo litigio tiene tres posibilidades de terminar la auto-composición (obra de las mismas pártes); la auto-defensa (obra de una. de las partes); y el Proceso (obra de las partes pero alcanzada medianteun tercero imparcial). 
En el campo penal pueden presentarse las tres situaciones, con la diferencia de que las dos primeras sólo se dan en determinados casos y como excepción; la más frecuente es el proceso.

En la represión del delito, el Estado recorre tres etapas fundamentales: $1^{\circ}$ el legislador describe los delitos y fija las penas; es función preventiva, abstracta. $2^{\circ}$ frente a un caso concreto, la función penal entra en acción: se determina la existencia del delito y se dicta la pena que corresponde, mediante juicio previo, como sanción a ese delito. $3^{\circ}$ procura la ejecución de la pena: aplica lo ordenado por el juzgador. All derecho penal corresponde la primera; al procedimiento penal corresponden las dos últimas etapas.

Florión define el proceso penal de la siguiente forma: "Es el conjunto de actividades y formas, mediante las cuales los órganos competentes, establecidos en la ley $\mathrm{y}$ observando ciertos requisitos, proveen la aplicación de la ley en un caso concreto" (1). Luego agrega: "El Derecho Procesal Penal es el conjunto de normas jurídicas que regulan y disciplinan el proceso, sea en su conjunto, sea en los actos particulares que lo integran". En todo proceso participan juez, ministerio público, inculpado y agraviado a los que se asignan derechos $y$ deberes. El agraviado puede constituírse en parte civil y en ciertos procesos, aparece la figura del tercero civilmente responsable. Considerado en su contenido formal, el proceso penal "se manifiesta como una relación jurídica que se desarrolla progresivamente entre varias personas ligadas por vínculos jurídicos. (2)

El proceso penal es el medio de hacer prevalecer el derecho como garantía del individuo; su finalidad es tutelar su derecho. No es defensa de la sociedad, porque ello legitimaría cualquier injusticia que en un momento dado se considerara necesaria. En cambio ef Derecho está por encima de las contingencias momentáneas de la sociedad, no toma en cuenta el carácter de la misma o su régimen político y sólo atiende a los principios inmutables de la Justicia.

Al tratar de la diferencia entre Derecho Penal y Derecho Procesal Penal, Carnelutti en sus Lecciones (3) dice que la diferencia radica entre "el derecho mientras se hace y el derecho después que se ha hecho". Luego agrega "en sentido más restringido, proceso significa el hacerse el derecho mediante el Juez, esto es, el proceso judicial". Es decir para Camelutti, Derecho Procesal "es el derecho que se hace mediante el proceso judicial".

El proceso penal es la segunda parte del "Fenómeno Penal" constituído por el delito y la pena: anverso y reversa de la medalla; punto de partida y punto de llegada. "No hay delito sin pena ni pena sin delito" (4). El Derecho Penal tiene como objeto establecer la existencia o inexistencia del delito y determinar la responsabilidad de su autor. Carnelutil en sus Lecciones citadas compara el Derecho Penal con la Patología y el Procesal con la Farmacología y dice que así como el estudio científico de la enfermedad ha precedido al de la medicina, lo mismo ha ocurrido con el delito respecto de la pena; asi como el estudio de la enfermedad no tendría ob- 
jeto $\sin$ el estudio del medicamento, asi también ocurre con el estudio del delito y de la pena.

Existe estrecha relación entre Proceso y Pena, aunque tengan significado diverso; proceso alude a evolución y pena a sufrimiento. Pero ambos conceptos terminan uno en el otro. La pena es consecuencia del delito y para su aplicación requiere una evolución. Desde la denuncia de la comisión de un delito hasta que se produzsa la condenạ, se suceden una serio de actos que reciben el nombre de proceso penal y que culminan en una sentencia condenatoria que señala la pena a cumplir o en una absolutoria que releva de todo cargo al procesado. No existe separación entre pena y proceso, porque la pena es el resultado de un proceso y el proceso tiene como consecuencia la imposición de la pena cuando se cumplen los fines del proceso, que son investigar el delito y la responsabilidad del delincuente. En última instancia ambos conceptos coinciden.

Pero además, de manera mediata, el proceso penal tiene otra finalidad: combatir el delito.

La sentencia que pone fin al proceso penal, explica el porqué de la pena. Quiere que el sentenciado comprenda la sanción que ha merecido su delito y mediante ello procure su enmienda, cuando salga. Además es un aviso y una prevención para quienes se sientan inclinados a la comisión de hechos delictuosos, haciéndoles ver que todo delito es castigado y que es muy difícil escapar a esta sanción. Esta es una finalidad muy importante porque la impunidad alienta la comisión de nuevos hechos delictuosos.

Además de esta finalidad, la sociedad, por su parte, se preocupa de hacer desaparecer las causas que favorecen la comisión de actos delictuosos. El Estado debe procurar condiciones de vida mejores para todos, evitando la desocupación y fijando condiciones de salario suficientes para que cubran las necesidades de una módica subsistencia. También debe alentar y proteger la acción social de la Iglesia quien procura fortalecer las disciplinas morales para fortalecer la voluntad y el querer de quienes por debilidad de carácter pueden caer en la comisión de delitos. El desarrollo de instituciones culturales, protección a las escuelas, creación de asilos, orfelinatos, etc. todo ello debe merecer la máxima protección estatal pues las buenas condiciones de vida $\mathrm{y}$ un alto índice de moralidad son los mejores elementos para desterrar los vicios y los hábitos delictuosos. Mediante estas protecciones, el Estado debe procurar que el delito resulte imposible o, por lo menos, de difícil realización. Esta es una función análoga a la que realiza la Higiene con respecto a la Salud Pública al procurar que desaparezcan las posibilidades de enfermedades.

Del análisis comparativo entre proceso penal y proceso civil, resultará la autonomía del primero con respecto del segundo. Florián y Castro (5) sostienen que pretender su identidad es tesis inadmisible porque son instituciones sustancialmente diferentes $y$ responden a propósitos distintos. El Catedrático del curso en la Universidad Católica Dr. Vargas Mata recogiendo los anteriores argumentos formula la siguiente síntesis comparativa: 
1. El proceso penal es campo de definición del derecho público $Y$ el proceso civil es campo de definición del derecho privado; pero como procesos ambos son disciplinas de derecho público.

2 . Eśta definición solo puede darse mediante el proceso; en el campo de derecho privado, ella puede darse sin necesidad de proceso.

$3^{\circ}$ Fines éticos sociales en el proceso penal; fines estrictamente jurídicos en el proceso civil.

$4^{\circ}$ El poder dispositivo de las partes es restringido en el proceso penal, siendo el Juez el único director de la instrucción; en cambio en el civil las partes tienen disponibilidad de las formas y términos, aunque no de manera absoluta.

$5^{\circ}$ Jueces permanentes y letrados e instancia única en el penal; en el civil hay varias instancias y posibilidad de arbitraje.

6. El proceso penal afecta necesariamente a la persona y es tomada en cuenta para los efectos de la sentencia y accesoriamente afecta $\alpha$ la cosa; en el civil la cosa es tomada en cuenta primordialmente y solo de manera accesoria la persona, pues solo cuentan los hechos.

$7^{\circ}$ El proceso penal solo actúa contra personas naturales; el civil contra toda clase de personas.

8' En el penal no hay debate contradictorio provocado por la lucha de dos intereses, siendo uno el interés: el de buscar la verdad; en el civil hay controversia y lucha de intereses económicos.

. $9^{\circ}$ El proceso penal se sigue en razón de un delito; en cambio el civil solo en razón de un derecho.

$10^{\circ}$ Para iniciar el próceso penal no es indispensable la identificación del sujeto pasivo (reo), puede serlo en el curso del mismo y solo será necesario conocerlo para los efectos del juzgamiento; en cambio en el civil desde su inicio es indispensable dirigir la acción contra persona determinada $e$ identificable.

$11^{\circ}$ La ejecución de la sentencia penal pertenece al Estado y afecta necesariamente a la persona del reo. La de la sentencia civil pertenece a la parte, que puede no hacerla efectiva $\mathrm{y}$, en todo caso, solo incide sobre el patrimonio del vencido, de manera que puede ser ilusoria desde el pun. to de vista económico.

Tales son las diferencias más saltantes entre ambos procesos. Ademós el proceso penal exige la colaboración de ciencias auxiliares que no son indispensables en el civil. 
Es cierto que existen muchos puntos comunes entre ambos procesos v.g. la prueba, la sentencia, etc. Pero ellos constiviyen puntos de contactos externos que no atañen al proceso mismo y nunca pueden constituir motivos que justifiquen la identidad.

\section{LASS PARTES DEL PROCESO PENAL. EL IMPUTADO. EL LESIONADO. EL MINISTERIO PUBLICO. EL TERCERO RESPONSABLE.}

En todo proceso -civil, penal, del trabajo o administrativo- existen tres sujetos: dos que contienden y uno que decide. Las partes que contienden reclaman una decisión jurisdiccional que resuelva la pretensión que se debate; el juez es el órgano que pronuncia esta decisión.

No hay proceso de una sola parte, pero tampoco hay proceso de más de dos partes. Cuando se dan más de dos personas, las restantes to man una u otra posición, alineándose $\alpha$ uno $u$ otro bando, sin constituir otra parte. En el proceso civil se presenta el Litis Consorcio activo y el pasivo; en el penal puede darse el caso de que existan varios imputados $\mathrm{y} / \mathrm{a}$ varios lesionados, pero cada uno de ellos toma una posición determinada por su situación en el proceso, oponiéndose a la imputación o sosteniendo esta en su cispecto particular, aunque sus intereses o derechos sean opuestos o dispares.

Ahora ha aparecido el tercero civilmente responsable que se alinea. al lado del imputado, puesto que su suerte, dentro del proceso penal, depende de la de éste, es decir la condena o absolución del imputado significa la condena o absolución del tercero, en el aspecto de la responsabilidad civil.

El problema de la capacidad de las partes, que reviste suma importancia en el proceso civil, no la tiene tanta en el penal, porque el juez penal suple los defectos en que incurren las partes en el ejercicio de sus derechos de defensa, actuando de oficio las pruebas necesarias para establecer la verdad.

Al tratar de este punto, Florián da la siguiente noción: "La capacidad procesal es la suma de condiciones necesarias para que aquel que ya es parte, pueda realizar actos procesales con eficacia jurídica" (6).

En siglos pasados era trecuente enjuiciar a animales y cosas inanimadas, situaciones que ya no se admiten. Ahora no existe discusión: solamente puede ser acusada de delito la persona natural. Esta regla general, en determinadas circunstancias, puede ser alterada por la minoría de edad, el mal estado de salud mental o por cualquier otra causa de inimputabilidad. En tales casos varía la índole del enjuiciamiento, se dan atenuantes $o$ eximentes de pena o sustitución de la misma por una medida de seguridad para el sujeto peligroso.

La capacidad de las personas jurídicas para actuar como sujetos activos de delito o para comparecer como agraviados en el proceso penal ha sido motivo de apasionado debate. La mayoría de los autores consi- 
dera que la responsabilidad penal es eminentemente personal y no cabe ampliarla a la ficción jurídica que es la persona moral; es el criterio que ha prevalecido en los códigos. Existen otros autores que estiman que si la persona jurídica puede contratar, también puede cometer delitos $\mathrm{y}$ en este caso, debe ser pasible de pena.

El ejercicio de la acción penal por las personas jurídicas no excluye la posibilidad de la acción reversiva por calumnia, como argumentan algunos tratadistas, porque de este delito responde el gestor que maliciosamente induce a que se formule la denuncia.

Indudablemente que solo la persona física puede sufrir una pena restrictiva de la libertad, como es la de prisión, penitenciaría, etc. La persona moral puede responder con su patrimonio, pero la intención delictuosa que es lo que acarrea la responsabilidad, solo la puede tener el ser humano inteligente $y$ que libremente se decide en favor $o$ en contra de un acto.

Técnicamente no se admite la responsabilidad penal de la persona jurídica porque éstas carecen de voluntad propia. Los actos por ellas ejecutados son inspirados por sus gestores y la responsabilidad penal recae sobre estos. En cambio para ser agraviado en un delito, no se necesita participación consciente en el mismo, cualquiera persona jurídica puede serlo en su patrimonio o en su prestigio.

Cuando una persona moral aparece cometiendo algún delito, la responsabilidad recae en el personero que la autorizó. No es poco frecuente el caso de gerentes $Y$ administradores de sociedades anónimas que, al descubrirse los delitos cometidos por estas entidades, ellos han respondido Y en tal condición han sido procesados. En cambio la persona jurídica como dueña de un patrimonio, puede resultar agraviada en delitos de este carácter $\mathrm{y}$ apersonarse en el proceso como parte civil, siempre mediante la representación física de su personero.

La capacidad procesal -idoneidad para actuar en juicio, resultante de sus cualidades personales- puede ser afectada por dos circunstancias: la edad y la salud mental. Hasta los 18 años, el individuo no puede ser pasible de pena, quedando sujeto a una jurisdicción especial. De oficio $y$ en cualquier estado del proceso en que se acredite la menor edad, el Juez cortará la instrucción, conforme lo ordena el art. 18, pasando lo actuado al Juzgado de Menores para que dicte las medidas protectoras requeridas. De los 18 años a los 21, la menor edad es atenuante que tiene consecuencias procesales y que se toma en cuenta al sentenciar. Los estados de anormalidad se refieren a la aptitud o discernimiento para delinquir, al desequilibrio mental que va desde la perturbación pasajera de la conciencia hasta la enajenación mental que lleva consigo la irresponsabilidad. Al tratar el art. 189, nos explayaremos en este punto.

De la responsabilidad penal del agente pasamos a la responsabilidad civil derivada del delito. En este lugar aparece la figura del Tercero Civilmente Responsable que significa la separación entre la capacidad penal del proceso con la responsabilidad civil proveniente del mismo hecho delictuoso, desplazada a tercera persona que, en la mayoría de los 
casos de accidentes automovilísticos, es el propietario del vehículo causante del atropello.

No todas las partes revisten igual importancia procesal. Unas -las llamadas principales- son indispensables para la existencia y desenvolvimiento del proceso: el Juez, el Ministerio Público y el procesado. Otras -las accesorias o secundarias- no tienen este carácter, interviniendo $\alpha$ su propio pedido o por citación de la justicia, pero cuya presencia no es indispensable en el curso de la instrucción, puesto que en muchas diligencias del proceso pueden prescindirse de ellas: la parte civil $y$ el tercero civilmente responsable.

El concepto de "parte" ha sido traslado del procedimiento civil donde actúa defendiendo intereses de carácter privado $y$ en actitud antagónica. Como en el proceso penal prevalecen los intereses públicos, se ha discutido si en él puede decirse que existen partes en el sentido que tienen en el derecho procesal. Algunos autores lo niegan. Como veremos luego, puede decirse que, desde determinado aspecto, existen partes en el proceso penal.

Es sabido que el derecho de sancionar corresponde al Estado, constituyendo al mismo tiempo un deber; a él le incumbe el ejercicio de la acción penal. Esta función la lleva a cabo mediante è Ministerio Público que en el desempeño de su cargo tiene facultades propias, adecuadas $\alpha$ su finalidad. Con toda propiedad Florián lo llama "parte en sentido particular y sui-géneris y -puede decirse- parte pública". (7)

Para Carnelutti las partes "son los sujetos de los intereses inmediatamente comprometidos en el conflicto" (8). Al cometerse un delito surgen: el heridor y el herido, el ladrón y el robado, el ofensor y el ofendido, etc. Producido el evento criminal, al Estado corresponde procurar su sanción; es un derecho y al mismo tiempo un deber, ejercido mediante la Ácción Penal. Esta función la realiza el Ministerio Público, investido de poderes especiales en el cumplimiento de sus atribuciones.

Imputado es la persona sujeta al proceso penal con miras a su ulterior sanción en virtud de la comisión de un hecho que la ley penal considera delito. Puede existir instrucción criminal sin imputado definido, pues el proceso tiene como fin establecer su identidad. El proceso penal es eminentemente práctico, sin tener fines especulativos; no persigue la declaración de derechos: se realiza ante la comisión de un delito con el abjeto de aplicar una sanción al culpable. En sentido estricto y gramatical Imputado es la persona contra quien se dirige una imputación y está sujeta a las resultas de un proceso. Debe existir coincidencia entre la person $\alpha$ imputada y la sometida a juicio. En el caso de ausentes, esta coincidencia debe darse en el nombre o en los signos descritos en la imputación. Como responsable del delito, el imputado es el sujeto pasivo de la relación procesal, el que ha puesto en movimiento la maquinaria judicial.

La parte lesionada que ha sufrido daño material con la comisión del delito, se denomina "agraviada", puesto que ha sufrido agravio. Siguiendo al código italiano, Carnelutti dice: "parte lesionada es quien en la imputación es indicado como ofendido por el delito". (9). Siempre está 
comprendido en el proceso. Así como no hay delito sin imputado, tampoco lo puede haber sin agraviado. En muchos casos es fácil determinar al ofendido, pero en algunos delitos es difícil, v.g. en el duelo, pero examinando el hecho, puede establecerse quien ha resultado agraviado con el delito.

Peró si bien es cierto que no cabe hablar en principio de delito sin imputado, ni realizar audiencia sin su presencia física - al menos en la legislación peruana- en cambio puede darse el caso, especialmente en delitos contra el patrimonio, de que exista delito e imputado y no aparezca quien es el ofendido. Puede ignorarse quien es la persona del agraviado y aun llegar a la sentencia con esta ignorancia. A veces la identificación del agraviado no es facil y procesalmente no es tan necesaria como la del reo, por su distinta situación legal.

La parte agraviada se convierte en Parte Civil cuando se apersona pretendiendo la reparación civil. En este caso, dice Carnelutti "tiene lugar un fenómeno de conmixtion del proceso penal con el proceso civil" (10). En el proceso penal se procura el resarcimiento del daño causado y nuestra ley penal en su art. 65 establece que "El Ministerio Público perseguirá conjuntamente con la represión, la efectividad de la reparación civil". La parte civil va más allá: persigue la adopción de medidas propias del proceso civil que tiendan a garantizar el pago del daño inferido. El ejercicio de esta actividad procesal elimina la posibilidad de pedir igual rescrcimiento en la vida civil.

Así como el lesionado puede convertirse en parte civil y también pueden hacerlo sus herederos, también puede darse el caso de que sea el mismo imputado quien responda económicamente por el daño inferido, -en el caso de los delitos culposos, si el propietario del vehículo es el causante del atropello-. Pero a veces es un tercero el propietario del vehículo automotor. Entonces aparece la figura del Tercero Civilmente Responsable a quien compete resarcir los daños inferidos al agraviado.

La comisión de todo delito implica la reparación del mismo. Conforme al art. 65 del Código Penal, esta reparación comprende "La restitución de la cosa; la reparación del daño causado; y la indemnización del perjuicio material o moral irrogado a la víctima del delito, a su familia - a un tercero". Todo resarcimiento económico se traduce en retribución económica, fijada prudencialmente por el Tribunal. Tiene tanta importancia la indemnización civil, que existe jurisprudencia uniforme en el sentido de que la sentencia que omite fijarla, es nula. Aun cuando se recuperaren las especies en su totalidad, siempre debe fijarse reparación por el daño moral irrogado con la comisión del hecho criminal. Su omisión acarrea la nulidad.

El dueño del vehículo es responsable indirecto por el pago de la reparación civil y por ello debe estar enterado, mediante notificación, de su situación procesal a fin de estar a derecho. La sentencia condenatoria que ordena el pago indemnizatorio lo obliga en forma solidaria con el reo, produce cosa juzgada en lo referente a este resarcimiento económico y si se ha ejercitado esta acción, impide renovarla en otra vía. Es decir 
el agraviado constituido en parte civil que cobra la indemnización, ya no puede reclamarla en la via civil.

\section{DEL OBJETO DEL PROCESO PENAL. OBJETO PRINCIPAL Y OBJETO SECUNDARIO. CONSECUENCIAS IMPORTANTES.}

El objeto es la materia que se discute en la instrucción $y$ que decide el Juez. Se distingue el Objeto Principal y el Accesorio o Secundario.

El Objeto Principal constituye el fondo del proceso, sin el cual éste no puede surgir. Consiste en la relación jurídica que nace al cometerse un hecho calificado como delito en la ley penal; se desarrolla entre el Estado y el autor del hecho; su contenido es la aplicación de la ley penal.

Ia inculpación es el presupuesto suficiente para el nacimiento de la relación procesal. No es necesario que ésta sea verdad concluyente y definitiva basta que se presente como hipótesis sujeta a investigación.

Esta relación jurídica es de derecho público. De allí derivan consecuencias importantes:

a) La no disponibilidad del objeto del proceso. Esta relación nace del hecho considerado delito, sin que las partes puedan cambiarla, alterarla o variarla: una sustracción siempre será robo $y$ no lesiones, una calumnia será calumnia y no injuria. I. Formulada la denuncia, no hay posibilidad de variarla. Las restricciones que las partes pueden imponer no varian el objeto de la relación, sino solo en lo accesorio, sin tocar el fondo del asunto; v.g. Ia reparación civil. Como hemos visto esta es una de las diferencias entre los procesos civil $y$ penal; mientras en el primero existe el poder de disposición sobre el objeto del proceso, en el segundo no. Esta no disponibilidad alcanza al Juez, quien si bien puede variar en algo la calificación, no lo es tanto como para cambiarla sustancialmente: v.g. abrir instrucción por delito contra el patrimonio para investigar una estafa o un robo o un hurto, pero nunca para un homicidio.

b) La inmutabilidad del objeto del proceso. La solución normal de la relación jurídica es la sentencia. Iniciada la relación, nada debe detenerla, no puede concluir en forma distinta que una sentencia, excepto en los casos de prescripción o de desistimiento en ciertos dełitos, en los que proceda el corte de la instrucción por matrimonio del ofensor con la ofendida, etc. Aunque exista acuerdo entre las partes, ello no impide que el proceso siga su curso: en el proceso penal no funciona que la parte agraviada se desista de la acción como medio de extinguirla o paralizarla. La sentencia es el único medio ordinario que tiene el proceso penal para terminar. Las excepciones funcionan en contados casos, que ya hemos reseñado. En materia civil en cualquier momento $\mathrm{y}$ en todas las acciones puede operar el desistimiento, el acuerdo de las partes, judicial o extrajudicial, la transacción, etc. lo que no ocurre en el penal. En materia civil cuándo existan menores interesados no es tan facil que se dé esta forma de con- 
cluir el proceso civil mediante no sentencia. Esta -como ya lo hemos dicho- es otra diferencia saltante entre ambos procesos.

c) La integridad del objeto del proceso. Los delitos en su oposición presentan un todo y solo considerados en su conjunto, es que cabe la exacta calificación del mismo. No es procesal denunciar o imputar un solo aspecto del hecho penal, silenciando otro u otros. Así por ejemplo si ha habido robo con violencia, no puede denunciar únicamente robo, pues el hecho estaría incompleto. La imputación que se formula debe ser por el hecho tal como ocurrió y que reviste determinado carácter delictuoso. Las denuncias deben ser por el delito íntegramente considerado, no solo por ciertos aspectos del hecho. Ello motivaria una sentencia que, por calificar parcialmente el delito, sería incompleta $Y$, ciertamente, injusta.

Al lado del objeto principal, surge un Objeto Áccesorio derivado del Principal. Como su nombre lo indica, el accesorio surge como consecuencia del principal. El Objeto Principal tiene existencia propia, con independencia del accesorio. Para la existencia del principal no es necesaria la del accesorio; en cambio para éste, es indispensable que exista el principal, del cual es derivación procesal.

En el Objeto Penal existe uno principal constituido por determinada relación jurídica penal. A su lado y como derivados existen. los secundarios o accesorios, que provienen de aquel $\mathrm{Y}$ de los cuales el Juez solo puede conocer en tanto que conozca del principal.

La forma más importante del Objeto Accesorio es la relación jurídica patrimonial destinada al resarcimiento económico del daño proveniente del delito. El evento criminal produce un daño público consistente en la alteración de la paz social, en la alarma que ha causado en la sociedad, en el temor que pueda repetirse contra otro miembro de la colectividad. Este es el dáño público que produce el delito y cuya sanción corresponde al Estcido por medio del Organo Jurisdiccional. Pero además surge otró daño: el particular, individual o colectivo, de carácter patrimonial. Al revés del civil, este daño reviste un interés cuasi público, porque está vinculado a la comisión de un delito y existe interés social en lograr una nepresión rápida y segura; involucrada a la sanción penal, está el resarcimiento del daño patrimonial. A la colectividad interesa restablecer la paz social alterada por el delito y también interesa indemnizar a la víctima del delito, completándose asi el restablecimiento del orden público. Por esta razón el Ministerio Público juntamente con la represión, persigue la indemnización del daño causado con el delito.

$A$ veces este resarcimiento es solidario entre el cutor del hecho $y$ un tercero, situación que puede darse en los delitos por negligencia. Surge entonces lo, figura del Tercero Civilmente Responsable, quien debe ser notificado de su situación procesal, en especial de la realización de la audiencia a fin de estar a derecho. Puede darse el caso de que este resarcimiento económico se persiga en la via civil, tanto por pretenderse fuertes sumas de dinero, cuanto por temerse una resolución desfavorable en la instrucción, cual sería la absolución o declaración de irresponsabilidad 
del encausado. Tales son las acciones civiles de indemnización que se siguen en la vía ordinaria.

Otra relación jurídica que constituye Objeto del Proceso, es resarcimiento del daño causado con el enjuiciamiento al encausado absuelto. Para que esta acción prospere se requiere que el inculpado después de haber sido absuelto, lo pida; y que exista negligencia o dolo en la injusta inculpación.

El estar procesado acarrea trastomos sociales,-pérdidas de tiempo y a veces hasta perjuicios económicos. La libertad de desplazamiento ha quedado disminuida; las citaciones judiciales le complican su vida y restan tranquilidad espiritual para el desarrollo normal de sus actividades diarias. Esto se agrava si en el curso del proceso, ha sufrido detención. Son indudables los perjuicios de todo orden que sufre quien ha sido sometido a un proceso penal $y$ es justo que, en su oportunidad, sea indemnizado.

La palabra "absolución" comprende no solo la que se dicta en una sentencia como culminación de un exhaustivo proceso investigatorio, sino también el auto del Tribunal Correccional que declara que no procede el juicio oral y ordena el archivamiento de la instrucción.

Pero es requisito esencial que exista negligencia -es decir precipitación- o dolo en la denuncia -es decir formulada a sabiendas de su falsedad-. No comprende a los innumerables casos en que por insuficiencia de pruebas, a pesar de existir el hecho punible, sin embargo no se ha establecido quienes sean los autores, ni por consiguiente la responsabilidad del o de los encausados. En tales casos no puede decirse que el proceso se ha debido a una injusta inculpación.

El Código Penal en su art. 404, inc. $1^{\circ}$, establece que la Caja de Indemnizaciones a las Víctimas del Delito, indemnizará también a los declarados inocentes en los juicios de revisión y a los absueltos por los Tribunales Correccionales, -en sentido amplio puede comprenderse a los casos antes citados-. Las leyes posteriores al Código (Nos. 10,234 Y 10,290) se refieren a esta institución y amplían sus alcances.

Otra relación que puede surgir -que no existe en la legislación. peruana- es la obligación del pago de la multa por un extraño al proceso, el que se encuentra ligado al acusado por vínculos civiles. Tal es la situación de quien comete un delito hallándose bajo la autoridad o vigilancia de otra persona; este pago solo procedería si el principal se hallaba obligado a hacerle observar a su dependiente o pupilo, aquellas normas cuya infracción acarreaba sanción penal. En realidad son casos de responsabilidad subsidiaria de carácter civil que reviste la forma de multa.

La última que puede presentarse, es el pago de Costas. Las Costas Procesales pueden ser de dos clases: Costas Generales: Ios gastos que realiza el Estado para el mantenimiento del organismo judicial y que al hacerlo cumple con una función propia; y las Costas Especiales, que son las que se originan en cada proceso y que son fáciles de individualizar: v.g. la pericia, el traslado de un testigo, etc. En caso de condena, son de cargo del sentenciado, si así se declarara en la sentencia. 
El art. 66 del Código Penal en su inciso tercero, establece que la reparación civil comprende: ......"La indemnización del perjuicio material 0 moral irrogado a la víctima del delito, a su familia o a un tercero". Dentro de este perjuicio puede considerarse -y así sucede en la práctica- el pago de los gastos hechos por la víctima con motivo del delito que se sanciona.

IV. DE LOS FINES DEL PROCESO PENAL. A) FINES GENERALES: MEDIATOS E INMEDIATOS. B) FINES ESPECIALES: DECLARACION DE CERTEZA; ALCANZAR LA VERDAD FORMAL; INDIVIDUALIZACION DEL AGENTE.

Los fines que pretende el Derecho Penal mediante el proceso, pueden dividirse en generales y específicos. Los generales se subdividen, a su vez, en mediatos e inmediatos.

Fines Generales. El fin general mediato o remoto coincide con el del Derecho Penal. Al procurar la defensa social; esta finalidad estó destinada a evitar la delincuencia. Desde este punto de vista, el Derecho Penal realiza una función análoga a la que lleva a cabo la Higiene en la salud corporal de los individuos: procura crear condiciones de vida social en virtud de las cuales desaparezca la posibilidad de nuevos delitos.

Además, al establecer la sanción, crea un poderoso contra-estímulo no solamente en quien la sufre, sino en los demás. En este sentido la prevención no solo se refiere a la persona del delincuente, sino a la sociedad en general. El efecto social de la pena, se extiende más allá del propio reo, alcanza a la colectividad que ve las graves consecuencias de infringir la norma penal. $\mathrm{Si}$ en muchos individuos los principios morales son débiles e insuficientes para mantenerlos dentro de la pacífica convivencia, el temor al castigo alcanza este resultado. Es, pues, una función de altá trascendencia social.

También la sociedad se defiende del delito mediante las Medidas de Seguridad que se dictan cuando existe la mera posibilidad de delito. Son preventivas, independientes de la calificación que puede darse al hecho y no están vinculadas al carácter delictuoso de alguna acción calificada con este nombre. Atiende únicamente a la peligrosidad que presenta el individuo, por cuya razón se le somete a estas medidas, evitándose que en el futuro pueda realizar actos ilícitos. La finalidad de estas medidas es la de excluir o, por lo menos, atenuar el peligro del delito, por lo que solo pueden dictarse cuando este peligro es evidente.

A primera vista parece que existiera cierta antitesis entre la prevención y la represión del delito. Pero examinando a fondo la cuestión, resulto que independientemente del peligro que surjan nuevos delitos, existe la necesidad de reprimir los ya producidos para restablecer el orden social alterado con su comisión. La prevención tiende a evitar la realización de delitos, para lo cual suprime las posibilidades, supresión que dada la natu- 
raleza humana y las cambiantes condiciones de-vida, nunca puede ser absoluta $\mathrm{y}$ total; podrán cerrarse muchas posibilidades pero siempre quedarán algunas que proveerán de delincuentes. Por ello puede afirmarse que prevención y represión son las dos caras de la lucha contra el crimen.

El fin general inmediato del proceso es la aplicación del Derecho Penal; es necesario que al delito siga la pena, de manera que no exista delito sin pena a fin de evitar la impunidad que tiene muy graves consecuencias de orden social. $\bar{A}$ veces el resultado del proceso no coincide con la verdad. Aquí aparece el error judicial. Si el juez fuera infalible, no habría sitio para el error judicial, pero no siéndolo siempre hay cabida para el equívoco, que puede ser positivo (afirmación de delito que no existe) o negativo (negación de delito que existe), es decir el delito queda sin pena $y$ hay casigo sin haber delito: se sanciona al inocente $y$ se absuelve al culpable. A la declaración de certeza positiva - que tiene como secuela Ia pena- se le llama Condena; a la declaración de certeza negativa se llama Absolución.

La finalidad represiva es muy importante en el proceso penal. Es la que justifica la existencia de la maquinaria judicial. La finalidad preventiva puede realizarse -aunque imperfectamente- sin el proceso; en carribio sin proceso penal no hay pena, no se da la finalidad represiva. La pena solcmente puede aplicarse mediante el proceso penal.

El proceso sirve principalmente para la aplicación de la ley penal en los casos particulares. Es la ley penal - general y abstracta- concretada ante un hecho del hombre. El proceso sigue una larga via antes de llegar a la pena: empieza calificando al hecho como delito; luego estableciendo que el presunto responsable es quien lo ha cometido; luego viendo si esta participación ha sido decisiva para el hecho o solamente accesoria, ayudando como cómplice u ocultando como encubridor; y finalmente concluye con la declaración de autoría y la imposición de la pena consiguiente.

Para Carnelutti (11) la finalidad del proceso penal es hacer que el "delito resulte inexistente". Si la prevención tiende a eliminar las posibilidades de dilinquir, la represión procura eliminar los factores individuales que hacen posible el delito, mediante la readaptación del sujeto. De esa manera la lucha contra el crimen se completa: segar las posibilidades del delito y eliminar los hechos delictuosos ya producidos. Son dos aspectos del mismo problema. Agrega este autor que la represión es al delito, lo que la Terapia a la salud corporal: procura que el delito $\mathrm{y}$ sus consecuencias desaparezcan.

La represión se funda en la necesidad de sancionar a aquel que ha inferido un daño con dolo o por culpa. Así como las medidas de seguridad constituyen la expresión más elocuente de la función preventiva del Derecho Penal, las medidas de penitencia -así llamadas por Camelutticorrientemente denominadas Penas, lo son de la función represiva. La finalidad de estas medidas penitenciales son procurar el arrepentimiento del reo $\mathrm{y}$ su futura readaptación. Toda pena debe procurar tres fines: prevenir el delito, restablecer el equilibrio social y enmendar al delincuente. 
El Derecho Penal supone que el hombre dotado de libre voluntad, puede determinarse por motivos que lo solicitan y la pena le hace ver que si se decide por aquellos que la ley califica de anti-sociales o malos, entonces le vendrá un castigo. Producido el delito, a pesar de la advertencia indicada y dictada la sanción correspondiente, queda restablecido el orden social. Entonces aparece la tercera finalidad de la pena, que no es la menos importante: procurar que el sentenciado se enmiende, arrepentido de su falta y resuelto a ser hombre de provecho en el futuro. Esta tercera finalidad intimamente vinculada a las anteriores, se cumple conjuntamente con ellas y al ejecutarse toda pena, se tiene en cuenta la posibilidad de enmienda y la necesidad del arrepentimiento. Para alcanzarla la ley pone elementos en manos del juzgador tanto al dictar la sentencia, como después, como es la Liberación Condicional, que es una gracia para quien ha demostrado posibilidad'es de readaptación social.

Los fines específicos del Proceso Penal de manera especial se refieren a la ordenación y desenvolvimiento de la instrucción y por ello Florián"(12) los califica de "métodos que han de seguirse para la consecución del fin general inmediato". Estos fines son: declaración de certeza, la verdad legal y la individualización de la personalidad del delincuente.

La Declaración de Certeza es uno de los fines específicos del proceso penal. No se puede imponer una sanción sin estar cierto que el acusado es quien debe ser penado como autor del delito cometido. El trabajo del juez consiste en confrontar el hecho concreto y real -el evento delictuoso- con el general señalado como pauta a la sociedad - la ley penal-. De esta confrontación nace una afirmación o negación: se ha cometido o no el delito. Antes del proceso es incierto decir si se ha cometida el delito, menos sindicar al autor. El proceso tiene esta finalidad: establecer la existencia del delito y la persona del autor. Concluido el proceso, se sabe a ciencia cierta. si ha existido delito y quien lo cometió. El resultado se llama Declaración de Certeza del Delito. Ell valor de esta declaración es análogo al que establece el legislador, pues obliga a las partes lo mismo que si fuera una ley. La declaración de certeza hecha por el juez es constitutiva de derecho: el hecho delictuoso declarado cierto produce efectos jurídicos.

En Derecho Penal existe el aforismo: no hay delito si no estó en el Código. Este principio tiene rígida aplicación en derecho sustantivo llegando el caso de que por ilícito que sea, si el hecho no está calificado expresamente como delito, no puede ser considerado como tal ni llegar a su juzgamiento. No cabe saricionar por analogía.

La certidumbre es la base de toda sentencia, es su fundamento indispensable, especialmente en los casos de condena. Faltando esta calidad se impone la absolución. Existen casos en que por no haber alcanzado esta certidumbre, el juzgador se ve obligado a absolver a un acusado.

Para que haya certeza se requiere un conjunto de motivos acreditados por la razón y la experiencia que sirvan de base a la, convicción; que las posibilidades contrarias hayan sido estudiadas y descartadas de manera que no exista duda alguna sobre la culpabilidad; que la convicción 
sea tal que la imposición de la pena se presente como la consecuenciá inevitable a ella, sin que motivos ajenos la desvirtúen.

Producir la certeza en el ánimo del Juzgador es la finalidad perseguida por la prueba. La declaración de certeza es la consecuencia lógica de toda la probanza. Es garantía de la organización judicial el saber que mientras no exista prueba suficiente, concluyente, no puede darse la Declaración de Certeza Positiva que lleva consigo la condena; que de lo contrario, cuando la duda es dueña de la conciencia del juez, entonces se produce la absolución en virtud del aforismo latino: In dubis reus est absolvendus, es decir en la duda se debe absolver.

La investigación de la Verdad Legal es otro de los fines específicos del proceso penal. Diversos medios probatorios son usados para que nuestro entendimiento alcance la certidumbre acerca de la realidad del hecho incriminado y de la persona del autor. En el curso del proceso penal, el Juez al reunir elementos, irá formándose criterio acerca del estado de las cosas y de la conducta de las personas. Desde la denuncia hasta la sentencia, el proceso atraviesa diversas etapas y mediante ellas el Juez pasa de la ignorancia absoluta hasta la evidencia.

La actividad encaminada a desarrollar la acción p̀enal, se llama Impulso Procesal. El proceso comina mediante trámites y actos procesales; se requiere que alguien se encargue de producirlos, es decir de impulsar el proceso. La doctrina reconoce dos sistemas: el inquisitivo que otorga al Juez facultad para imprimir por si el impulso debido, mediante requerimiento $\alpha$ las partes y adoptando las medidas que estime oportunas con miras a lograr una solución rápida y justa; y el dispositivo en el cual la facultad de mover el proceso pertenece exclusivamente a las partes. En nuestro procedimiento penal predomina el Inquisitivo aunque existen normas de carácter dispositivo.

El juez empieza por admitir la posibilidad del delito y de la culpabilidad; es la consecuencia de la denuncia. Frente a ella considerará la posibilidad de que realmente exista delito $y$ que el imputado sea delincuente. La posibilidad es una fórmula vacía que se sustenta en la acusación de parte interesada. En potencia contiene la acusación y la responsabilidad.

La probabilidad es la segunda etapa hacia la consecución de la Verdad. "Es lo fluctuante entre lo posible y lo evidente" dice el Dr. Zavala Loayza (13). En la búsqueda de la verdad, las posibilidades se desechan o se amparan y cada una de ellas aporta una posibilidad en la tesis de la culpa y del delito.

La evidencia es el tercer $y$ último grado del conocimiento, al cual se llega después de pasar por la posibilidad y la probabilidad. Constituye la certidumbre a que debe aspirarse.

Estos grados del conocimiento están vinculados a los estados subjetivos de duda, suposición y certeza. La denuncia es considerada como posible verdad y genera la duda. Ante la imputación aparece la duda acerca de que si seró cierta la existencia del delito y que el autor sea el imputado. De la duda pasamos a la suposición: ante los cargos presen- 
tados nos inclinamos a creer que son ciertos. Esta suposición se convierte en certeza cuando adquirimos evidencia de que el hecho denunciado como delito lo sea efectivamente $y$ el autor es aquel a quien se le imputa. La certeza es un estado de conciencia que ve elaro, con convicción de estar en lo cierto.

Este proceso del conocimiento nos lleva $\alpha$ la verdad. La verdad es la concordancia entre el hecho y la representación que de él tiene nuestro entendimiento. La verdad absoluta es inalcanzable para el ser humano, poseedor de inteligencia limitada y sujeto a imperfecciones. La Verdad AbsoIuta es Dios y solo la posee la Divinidad. El hombre, de esencia imperfecta, nunca la puede poseer por la misma limitación de sus facultades intelectuales.

La administración de justicia debe limitarse a la Verdad Legal, aquella a la cual se puede alcanzar mediante el entendimiento. Es la que aparece en los procesos como resultado de la probanza actuada dentro de cauces legales. Siempre tiene una variable proporción de error. Se lucha contra el error judicial de dos maneras: el magistrado procurando una más completa formación jurídica que dé el necesario criterio jurídico; la ley penal creando el instituto de la Revisión para los casos en que el error aparezca flagrante $y$ en los cuales se autoriza a reabrir el proceso de concluyo por condena. Es excepción a la Cosa Juzgada en aras a procurar una más exacta justicia humana.

Establecer la Personalidad del Procesado es otro de los fines específicos del proceso penal. El Derecho Penal modemo está penetrado de-la idea de la individualización de la pena y el único modo de alcanzarla, es individualizando al delincuente. Las ciencias penales como la Sociología, la Sicología, la Antropología y la Caracterología Criminales son excelentes medios técnicos que el juez tiene a su alcance para lograr este conocimiento. La declaración de "especialmente peligroso" de que habla la ley penal, solo tiene explicación si media estudio acerca de la personalidad del agente infractor.

Lo frecuente es que la sentencia concluya en una pena $a$ recomiende una medida de seguridad. En uno $y$ otro caso es indispensable establecer la verdadera personalidad del reo.

Nuestro Código Penal dispone que la pena debe ser adecuada $\alpha$ las condiciones personalesadel encausado. En el art. 51 declara que: "Para la aplicación de la pena, los jueces apreciarón la culpabilidad y el peligro del agente, teniendo en cuenta las siguientes circunstancias" y luego enumera las condiciones personales del autor, el medio ambiente, la educación, las condiciones en que hubiere perpetrado el delito, etc.

Estas condiciones de culpabilidad son muy importantes de establecer, porque conforme al art. 50, los jueces "aplicarán el máximum o el mínimum señalado por la ley para el délito". Existiendo en nuestro código el sistema de penas-topes dentro de las que fluctúa el arbitrio judicial, la apreciación del juẹ en cada caso será la que determine la pena a impaner. Por ello reviste tanta importancia conocer la personalidad del sujeto pasible de pena. 
La individualización de la personalidad del delincuente es también necesaria para determinar las condiciones de ejecución de la pena.

El proceso no puede limitarse a establecer la verdad del hecho contenido en lá denuncia; debe establecer además la identidad, la individualización de su autor. Este fin tiene dos consecuencias: $1^{\circ}$ evitar la condena de un inocente; y $2^{\circ}$ conocer las calidades del agente que permitan al juez adaptar la pena al grado de su responsabilidad. Con este propósito $\in$ l juez debe estar facultado para utilizar todos los medios posibles de identificación. La evolución de estos medios, que partieron del juicio de Dios, pasando por la antropometría y la dactiloscopia, llegan hoy a otros sistemas científicos comó la agrupación de los poros, la coloración y ramificación vascuíar del ojo, culminando con la fórmula sanguínea.

Es, pues, necesario conocer de manera completa al hombre a juzgar, fijar sus condiciones personales, sus reacciones frente a los estímulos sociales, su conducta anterior al delito y la posterior después de cometido éste, el medio ambiente en que se ha desarrollado, la educación recibida, el hogar en que ha vivido, etc. datos todos indispensables si es que queremos procurar su readaptación social.

En nuestro procedimiento penal, el Juez tiene facultad para ordenar exámenes, peritajes, reconocimientos y esiudios de la persona del procesado, bien sea a pedido de parte o de oficio. En este punto no tiene otra limitación que no atentar contra los fines propios del proceso respetando la persona humana.

De esta manera la ley proporciona al juzgador los medios necesarios para alcanzar el completo conocimiento de la persona sometida a su decisión.

\section{FORMAS EXTERNAS DEL PROCESO PENAL. A) PRINCIPALES: FUN- CION DE ACUSAR; FUNCION DE DEFENSA; FUNCION DE DECISION. B) SECUNDARIAS: ORALIDAD Y ESCRITURA; PUBLICIDAD Y SECRETO.}

Las formas principales del proceso penal se reducen a las tres etapas esenciales, a saber:

La función acusatoria que contiene la imputación concreta de un delito y puede ser formulada por el Ministerio Público, la autoridad política o el propio agraviado. Es la primera etapa, previa a todo proceso y dura mientras existe este.

La función de defensa nace como consecuencia de la anterior. Todo aquel a quien se imputa la comisión de un delito, tiene su derecho expedito para rebatirlo. No hay proceso si falta esta función. La defensa es derecho inherente a la persona humana y no puede expedirse sentencia si el reo ha estado privado de ella. Es irrenunciable, en especial en la última etapa del proceso penal. 
Ia tercera función es la de decisión. Uno de los fines del proceso es establecer la relación de derecho penal que nace por la infracción de la ley y concluye con la declaración de certeza respectiva.

Cuando prevalece la distinción de funciones $\mathrm{y}$ existen los tres órganos correspondientes, tenemos el proceso acusatorio. Si prevalece la función del juez, el proceso será inquisitivo. Casi nunca se da la forma inquisitiva o acusatoria pura; lo general es que se mezclen ambas. Ninguno de estos sistemas de enjuiciamiento por si solo puede llenar las necesidades de la defensa social. Por ello, tomando algo de cada uno se ha formado el sistema denominado Mixto. De él afirma Castro (14) consiste (el mixfo) en dividir el procedimiento penal en dos partes: la primera es la instrucción o sumario; la segunda es la discusión o de plenario. La primera presenta los caracteres del sistema inquisitivo (secreto $y$ escrito) $y$ la segunda los del acusatorio (oral, contradictorio y público)".

Esta forma mixta domina en nuestro sistema. La instrucción reposa en la forma inquisitiva, pero no tiene una forma pura por cuanto cada función tiene órgano propio, aunque su actividad esté controlada por el juez; el art. 49 declara que "el juez es el director de la instrucción y como tal le corresponde...". La posición del juez es preponderante y tiene poderes casi absolutos, sin otra limitación que no atentar contra los fines del proceso.

En el juicio oral domina el sistema acusatorio, con el debate contradictorio que se lleva a cabo en la audiencia. Las pruebas acumuladas en la instrucción no siempre constituyen el único fundamento de la sentencia; lo actuado en el juicio oral tiene enorme importancia $y$ puede destruir el valor de las pruebas actuadas ante el Juez, tanto más si ante el Tribunal se han actuado nuevas pruebas. Esta etapa tampoco tiene una forma pura, por cuanto las partes no tienen el control del juicio, el que es dirigido $y$ orientado por el Tribunal.

El Dr. Zavala Loaiza (15) considera que nuestro sistema procesal es algo más que la mezcla del ínquisitivo $\mathrm{y}$ del acusatorio. Lo calífica de un proceso penal ordenado en dos etapas sometidas "a las leyes procesales del análisis y censura".

Las formas secundarias tienen función accesoria en el proceso penal y sirven para expresar su contenido. Resuelven dos problemas:

a) Fijan las relaciones entre las personas que intervienen en el proceso.

b) establecen quienes pueden asistix a los actos del proceso.

Desde el punto de vista del medio físico en que se graba las declaraciones, existe la fómula de la oralidad o la de la escritura. Cada uno de estos dos sistemas ofrece sus ventajas y sirve en su caso. Así la espontaneidad en la declaración se logra mejor mediante la oralidad. En cambio la escritura invita a la reflexión $y$ las declaraciones resultan mejor pensadas. Pero no hay sistema puro, pues según sea el caso se usaró uno u otro: así las órdenes que dicta el director de debates en 
la audiencia son orales, porque la rapidez así lo exige; en cambio la sentencia siempre será escrita. No hay separación rígida entre ambos sistemas, no dándose uno con exclusión del otro. En nuestro proceso, la primera fase es predominantemente escrita y la segunda oral, sin que ello signifique que en la instrucción no existan diligencias orales que luego se trasladan al papel ni en la audiencia la lectura de piezas del proceso, de lo que queda constancia en el acta respectiva.

El segundo problema se vincula al conocimiento que pueden tener las demás personas de lo ocurrido en el proceso. La publicidad y el secreto tienen sus ventajas y sus defensores. La publicidad de lo actuado ante la justicia calma el natural sentimiento de indignación $\mathrm{y}$ de castigo que siente el pueblo ante la comisión de crímenes y desanima a otros que, quizós sin tal estímulo, seguirían igual camino; también impone respeto por la justicia haciendo ver al público cuales son sus desvelos y preocupaciones. Pero por otra parte esta misma publicidad orienta a quienes oculian los hechos permitiendo la fuga del autor o su ocultamiento; también daña el honor de quien se imputa-ser autor que quizás más tarde puede quedar libre al comprobarse su inocencia, pero como muchos recordarón la imputación que tuvo resonancia periodística y no conocerán la absolución, su honor sufrirá y quedorá mancillado.- En cuanto al secreto, si éste fuere absoluto reviviría el antiguo proceso inquisitorial, regresando a etapas ya superadas, pero es indudable que en muchas circunstancias ese secreto contribuye al total esclarecimiento de los hechos $y$ beneficia a la misma justicia. Por eso puede afirmarse que la publicidad y el secreto son dos posiciones extremas que no han prevalecido en forma absoluta. Con respecto a este punto, dice Carnelutti: "Una secular experiencia $\mathrm{y}$ una fácil reflexión muestran que las ventajas del secreto son apropiadas para el primer período del proceso en el cual cuimina la necesidad de recoger las pruebas; y las de la publicidad para el segundo en el cual, por el contrario, el cometido principal está en derivar de las pruebas las razones de certeza en torno al acaecimiento del delito ... . La instrucción, por tanto, está dominada por el principio del secreto; el debate, por el de la publicidad". (16)

Conforme al art. 73 "La instrucción tiene carácter reservado" quedando al criterio del juez fijar los límites de esta reserva. En todo caso ella cesa al dar término a la instrucción para ser elevada al Tribunal.

La publicidad es esencial para el acto oral, constituyendo garantía amparada por la Constitución Nacional. Por causas contempladas en la ley, este principio sufre restricciones: tales son los casos de delitos exceptuados, en querellas que atenten contra el honor de la víctima o en casas que el mismo Tribunal así lo acuerde en resguardo de la moralidad pública. (Ãrt. 215).

El secreto es obligatorio guardarlo para quienes intervienen en el proceso y mientras dura la instrucción. (Art. 134).

El Dr. Zavala Loaiza expone que la instrucción es reservada pero no secreta porque la conocen. las partes que intervienen en el proceso: el secreto absoluto sólo se da en muy contados casos. No es pública por- 
que la publicidad estorbaría la investigación judicial, permitiendo al procesado y a sus cómplices ocultar las pruebas que les perjudiquen, urdir tramas $\mathrm{y}$ hacer desaparecer las huellas del delito. En realidad la publicidad atentaría contra los fines del proceso, por cuanto dificultaría o haría imposible la investigación de la verdad. Por ello considera que la reserva sirve a la finalidad perseguida en el proceso penal, sin que llegue al hermetismo del desprestigiado proceso inquisitorial.

Las partes tienen restringido poder de disposición sobre las formas: del proceso, por cuanto éstas alañen a la esencia del mismo. Por regla general, las disposiciones son de observancia obligatoria $Y$ las partes poco o nada pueden hacer para alterarlas o suprimirlas. Por excepción la parte puede asistir o no a diligencia no importante v. g. ratificación de documento, pero acarrea la nulidad si el reo carece de defensor en la audiencia.

\section{EXTINCION DEL PROCEDIMIENTO PENAL. CAUSAS COMUNES APLICABLES A LA ACCION PUBLICA Y A LA PRIVADA. CAUSAS EX- CLUSIVAS DE CADA ACCION. CAUSAS COMUNES A TODAS LAS ACCIONES.}

El procedimiento se extingue al mismo tiempo que la acción penal, pues su finalidad es permitir el movimiento de ésta. Nuestro Código Penal en su Título XV del Libro Primero se ocupa conjuntamente de estas causas $\sin$ diferenciarlas. Por razones expositivas $y$ siguiendo a los autores. de la materia, haremos la división antes indicada, basándonos en sus no tas características.

A.-Ccusas de extinción comunes a las acciones pública $Y$ privada.

Ellas son: muerte del encausado, amnistía $y$ en ciertos delitos contra la honestidad, perseguibles a instancia del agraviado, el desistimiento y el matrimonio subsiguiente con la agraviada.

So acepta universalmente que con la muerte se extingue la acción. penal. Pasó la época en que se juzgaba a cadáveres y en la cual los difuntos no escapaban a la humillación, pues sus efigies eran sacadas en procesión para afrenta de su honra y.reputación. En derecho moderno, la muerte marca el fin de la personalidad y de la responsabilidad penal, la que es eminentemente personal.

La aministía "suprime legalmente el hecho punible" dice el art. 126 del Código Penal. No habiendo delito, no hay nada que reprimir. Es el olvido del acto incriminado y borra retroactivamente la falta cometida.

En delitos contra la honestidad cuando la agraviada es mayor do. 16 años, se requiere instancia de parte para poder iniciar Ia acción, siempre que no medie violencia. El art. 313 del C. P. P. establece que puedo cesar "por renuncia de la parte agraviada", la que antes de ser aceptada, deberá apreciarla prudencialmente el Tribunal, considerando especialmente "los móvilles del desistimiento" dice la ley. El interés social 
deberá orientar la acción de los jueces para aceptar o rechazar tales renuncias.

Cuando la agraviada se encuentra en edad núbil, puedde aceptarse su matrimonio con el encausado, en cuyo caso éste "quedarḱ exento de pena" según dispone la segunda parte del art. 204 del C. P.

Tanto la amnistía como la muerte dejan subsistente la acción civil proveniente de delito, la misma que puede hacerse valer en la via correspondiente. Esta será la civil por haber concluido la instrucción criminal.

B.-Causas exclusivas de la Acción Penal.

Son dos: la renuncia del agraviado; y la retractación del ofensor. Funcionan en los delitos de acción privada en los cuales el impulso pracesal está a cargo de las partes. Se supone que la sociedad no ha sido grovemente afectada con la comisión del hecho incriminado y al darse la renuncia o la retractación, se supone que la parte agraviada ha quedado satisfecha.

Pero también estas causas de extinción son atacadas por conocidos tratadistas por estimar que se encuentra lejana la época de la venganza privada y que hoy el Derecho Penal se funda en la defensa social y debe perseguirse todo delito, quiéralo o no el agraviado, puesto que es la misma sociedad la perjudicada. Una vez puesta en movimiento la maquinaria judicial, ésta no puede quedar a merced del capricho de los interesados.

Nuestro Código Penal solo considera como posibilidad de hacer cesar la acción penal, la renuncia del agraviado en los delitos de acción privada. Como excepción a éste principio general, tenemos el delito de adulterio en el cual "El Cónyuge ofendido puede en cualquier tiempo remitir la pena a su cónyuge" (art. 213). Esta excepción proviene de la especial naturaleza de este delito y la conveniencia social de que el perdón del cónyuge inocente pueda rehabilitar al culpable, restableciendo la unión familiăr.

En los delitos de acción privada que se inician mediante querella, antes de realizar el comparendo "el juez invitará a las partes a conciliarse" (art. 306 C. P. P.). Esta conciliación radica en la retractación del ofensor y extingue la acción penal, concluyendo el proceso con la firma del acta respectiva en la cual consta la conciliación.

C.-Causas exclusivas de la Acción Civil.

Las causas propias de la extinción de la Acción Civil son: la renuncia y la transacción.

Renuncia es la dejación voluntaria y consciente que se hace de alguna cosa o derecho adquirido. Como único requisito basta la voluntad del renunciante. Puede manifestarse explícitamente mediante declaración de voluntad escrita o verbal, o implícitamente en que falta tal declaración pero los hechos demuestran la intención de manera indubitable.

Nuestro Código Penal no acepta la renuncia del agraviado como extinción de la acción civil y repetidas ejecutorias supremas establecen que ésta es irrenunciable. (A. J. 1942 págs. 91; de 1944 pág. 95). Pero a veces cuando se ha indemnizado al agraviado constando en escritura pública o en escrito con firma legalizada, ésta renuncia a la indemnización por haber sido resarcido económicamente del daño sufrido. En estos casos 
el Tribunal Correcciónal siempre fija la reparación civil -que también comprende el daño moral- disminuyéndola prudencialmente.

Es frecuente que el agraviado no cobre la indemnización señalada en la sentencia, sea por ignorancia, por negligencia o por evitarse molestias derivadas de los requerimientos necesarios en todo cobro. Este es el caso de la renuncia implícita, porque tácitamente el agraviado ha hecho abandono de la reparación que se le ha señalado y a la cual tiene el derecho que emana de una sentencia judicial.

El principio general es que la intención de renunciar no se presume, salvo que actos posteriores -como es no cobrar una reparación civil fijada en sentencia- demuestran que el perjudicado no tiene intención de hacerla efectiva. Con el abandono, implícitamente se establece la intención de renunciar al cobro.

La ejecutoria suprema de 5 de mayo de 1955 (A. J. pg. 95) dice que la reparación civil forma un todo con la pena y que, por consiguiente, no es renunciable. La omisión de fijar esta cuantía acarrea la nulidad de la sentencia. No puede existir renuncia expresa, pues de darse no sería tomada en cuenta por el juzgador, pero como nadie está obligado a cobrar una deuda, si en la sentencia se fija la reparación civil y el agraviado no la cobra, entonces se produce el abandono y se aplica lo dispuesto en el inc. d, del art. 403 del C. P. remitiéndose el importe al Consejo Local de Patronato para incrementar los fondos de la Caja de Indemnizaciones a las víctimas del delito. Esto puede calificarse de renuncia implícita; el no cobrarla hace presumir que se renuncia $\alpha$ ella.

La Transacción es otro de los medios legales de extinción de la acción civil. El art. 76 del C. P. establece que "Es nulo todo contrato entre el damnificado $y$ el delincuente sobre la reparación civil".

Conforme a esta disposición legal, no puede existir transacción válida entre el acusado y la víctima. Pero con frecuencia se produce el acuerdo entre ambos sobre el monto de la reparación civil, firmándose la correspondiente escritura pública con la entrega respectiva. Este acuerdo previo a ta terminación de la instrucción, es beneficioso para el agraviado, pues recibe el dinero en momento oportuno, cuando lo necesita para su curación, evitóndose la inevitable demora que acarrea todo proceso judicial. El Tribunal Correccional no puede impedir el acuerdo entre las partes, pero aplicando el art. 76 no le otorga valor alguno y siempre tendrá que fijar determinada cantidad por concepto de reparación civil en la sentencia respectiva. Indudablemente que el monto que señale por este concepto, tendrá carácter simbólico.

Surge la interrogante si concluído el proceso penal y dictada sentencia, reo y agraviado pueden transigir sobre el monto de la indemnización fijada por el Tribunal?. Creemos que no, porque la redacción del citado art. 76 es amplia $y$ no distingue si es procesado o condenado. Pero es claro que en la práctica puede llegarse a un acuerdo entre las partes para el pago recortado, que en realidad constituye una transacción y no pedirle autorización al Tribunal. En este caso el agraviado siempre tendrá su acción expedita para reclamar la diferencia no pagada.

En conclusión, la transacción no está permitida en nuestra legis- 
lación penal. Pero sí, al margen del Tribunal, se produce la transacción, es indudable que éste la tomará en cuenta para fijar el monto de la reparación civil.

D.-Causas de extinción comines a toda acción.

Las causas comunes a todas las acciones, públicas, privadas y civil de indemnización, son: la cosa juzgada y la prescripción.

El principio de la Cosa Juzgada es regla dè derecho aceptada universalmente. Es móxima constante que el criminal juzgado conforme a una ley, no puede ser perseguido por segunda vez, por el mismo delito. No importa que la pena impuesta sea prisión o peniterciaría, ni aun que haya sido absuelto o condenado. Existiendo sentencia - de la clase que sease estima que ha sido reparada la ofensa inferida a la sociedad, que el reo ha pagado la deuda contraida con la colectividad y que en adelante queda libire de todo cargo.

La respetabilidad de los fallos es salvaguarda de todos los derechos y de todos los intereses. La firmeza del derecho declarado en sentencia judicial radica en la Cosa Juzgada. Es necesario que todo proceso tenga fin. Cuando las partes en conflicto han agotado los recursos legales, la decisión judicial que sobreviene como conclusión del litigio es irrevocable, inalterable, nada ni nadie la cambia. El proceso ha terminado y lo resuelto es la Verdad Legal que para la sociedad constituye la única a la cual puede aspirarse. La Cosa Juzgada ha sido norma constante desde el Derecho Romano, existiendo en todas las legislaciones posteriores y pasando hasta las actuales. Esto proviene de que la Cosa Juzgada responde a una necesidad. social.

Dada la amplitud de su fundamento, la Cosa Juzgada abarca toda clase de acciones, sin distinguir unas de otras. Se aplica en las sentencias nacionales y se reconoce que hay Cosa Juzgada cuando el delincuente ha sido sentenciado válidamente en el extranjero. La sentencia extranjera lo ampara, evitándose nuevo juzgamiento por los tribunales peruanos.

El art. 118 del C. P. reconoce que la Cosa Juzgada es uno de los medios de hacer cesar la posibilidad de iniciar la acción penal.

La sucesión de las cosas en el tiempo es la medida del movimiento. El factor tiempo ejerce influencia decisiva en la adquisición y pérdida de los derechos, convalidación, modificación y extinción de los mismos. El mero discurrir de los días da origen a nuevos derechos o acarrea la variación o pérdida de los mismos. Así como el tiempo influye en los derechos, también influye en las acciones. Las acciones deben ejercerse en plazo predeterminado, actuar dentro de los términos que fija la ley y la inacción acarrea su extinción. Es principio universal de derecho que las acciones no deben quedar permanentemente abiertas, que debe llegar algún momento en que su no uso acarree la pérdida del derecho de ejercicio. Basado en este principio es que existe la Institución de la Prescripción.

El fundamento de la Prescripción no reside en el Derecho Natural y ello ocasiona la controversia sobre su moralidad y conveniencia. Se fundamenta en la suposición de que el poseedor de una acción que no la ejercita durante dilatado tiempo, es porque tiene intención manifiesta de hacer dejación de la misma. También se dice que es conveniencia social dar esta- 
bilidad y firmeza a ciertas situaciones de hecho convirtiéndolas en situaciones de derecho. En realidad son razones de necesidad social las que justifican esta Institución y la impuesta en todas las naciones del mundo. civilizado.

En el antiguo Derecho Romano todas las acciones eran imprescriptibles, es decir perpetuas; a pesar de ello los Pretores fijaban plazo dentro del cual debían ejercitarse; transcurrido éste, el demandado podía oponer la Prescriptio Temporis; en el Imperio se fijan plazos para la prescripción de las acciones reales en diez $y$ veinte años según fuera entre presentes o ausentes, respectivamente. Para que funcionara la prescripción se exigía que ésta fuese contínua, es decir que no se interrumpiese ni civil ni naturalmente por reconocimiento expreso o tácito del deudor. El Derecho Español y posteriormente el de todo el mundo civilizado, ha recogido esta tendencia, señalando plazo para la prescripción de acciones.

La Institución de la Prescripción es una, no diferenciándose la civil de la penal, variando únicamente el plazo. El hecho extintivo lo constituye la inactividad del ejercicio del derecho por tiempo dilatado, calificándolo así la autoridad judicial. En materia penal existe la prescripción de la acción penal y la prescripción de la pena; en ésta última los plazos son mayores que en la primera.

La prescripción es un hecho extintivo cuya influencia se manifiesta en todos los delitos. Existen hechos extintivos particulares, aplicalles únicamente a determinado delito v.g. en caso de adulterio, procede la remisión o perdón de parte del cónyuge ofendido. Los hechos extintivos generales comprenden a todos los delitos, sin excepción alguna.

La institución de la prescripción está legislada en el Derecho Penal sustantivo. Según el art. 118 la posibilidad de iniciar la ación penal o de pronunciar sentencia cesa, entre otros motivos, por la prescripción. El plazo varía según se trate de la acción propiamente dicha o de la ejecución de la pena. También varía atendiendo a la gravedad del delito o de la pena dictada, según sea esta prisión, penitenciaría o multa.

\section{BIBLIOGRAFIA}

$16^{\circ}$ Carnelutti pág. 145, tomo III.

idem. pág. 15. idem. pác. 69 tomo I.

Florián. obra citada. pág. 20

idem. pág. 94.

idem. pág. 93.

Carnelutti obra citada pág. 190. I.

idem. pág. $205 \mathrm{I}$.

idem. pág. $210 \mathrm{I}$.

idem. pág. 104 I.

Florián. ob. citd. pág. 59.

Zcrvala Loaiza pág. 34.

Derecho Procesal Penal por Eugenio Florián. pág. 14.

Lecciones sobre el Proceso Penal por Francesco Carnelutti, pág. 57. I.

El proceso penal y sus problemas por Carlos Zavala Loaiza pág. 59.

Derecho Procesol Penal por Máximo Castro pág. 17 tomo II. 